\title{
Ammonia volatilization from arable land after application of cattle slurry. 2. Derivation of a transfer model
}

\author{
J. VAN DER MOLEN ${ }^{1 *}$, A. C. M. BELJAARS ${ }^{2 * *}$, W. J. CHARDONı, \\ W. A. JURY ${ }^{3} \&$ H. G. VAN FAASSEN 1
}

1 Institute for Soil Fertility Research, P.O. Box 30003, NL 9750 RA Haren, Netherlands

2 Royal Netherlands Meteorological Institute, P.O. Box 201, NL 3730 AE De Bilt, Netherlands

3 University of California, Department of Soil and Environmental Sciences, Riverside, CA 92521, USA

Received 18 January 1990; accepted 19 March 1990

\begin{abstract}
Ammonia, volatilized from animal manures after land-spreading, is one of the major sources of acid deposition in the Netherlands. A model for transfer of ammonia from arable land to the atmosphere after surface application or incorporation of cattle slurry is presented. The model can be used to study the interactions of the chemical, physical and environmental factors influencing volatilization losses and their combined influence on $\mathrm{NH}_{3}$ volatilization under field conditions. The model employs the following flux equation: $R=k\left(C_{\mathrm{s}}-C_{\mathrm{a}}\right)$ where $k$ is a transfer function, $C_{\mathrm{s}}$ is the $\mathrm{NH}_{3(\mathrm{~g})}$ surface concentration and $C_{\mathrm{a}}$ is the atmospheric $\mathrm{NH}_{3(\mathrm{~g})}$ background concentration. The rate of volatilization $R$ can be calculated at any moment after application, provided $k, C_{\mathrm{s}}$ and $C_{\mathrm{a}}$ are known at this moment. The model therefore basically consists of modules which yield these variables.
\end{abstract}

Keywords: ammonia volatilization, transfer model, cattle slurry, arable land, surface application, incorporation

\section{Introduction}

Annual ammonia $\left(\mathrm{NH}_{3}\right)$ emissions from liquid animal manures in the Netherlands are estimated to be $2.5 \times 10^{5} \mathrm{Mg}$. A substantial part of the $\mathrm{NH}_{3}$ is deposited on nearby sites, and contributes to soil acidification upon transformation into $\mathrm{HNO}_{3}$ through nitrification. It is estimated that volatilization of $\mathrm{NH}_{3}$ after landapplication of cattle slurry constitutes $30 \%$ of the total emission.

\footnotetext{
* Present affiliation: TAUW Infra Consult BV, P.O. Box 479, NL 7400 AL Deventer, Netherlands. ** Present affiliation: European Centre for Medium-Range Weather Forecasts, Shinfield Park, Reading, Berkshire, RG2 9AX, UK.
} 
Results of field experiments on $\mathrm{NH}_{3}$ volatilization after application of cattle slurry to arable land have been reported by Beauchamp et al. (1982) and van der Molen et al. (1989; 1990). As the interactions involved in the $\mathrm{NH}_{3}$-volatilization process are very complex, modelling the process has become a prerequisite for understanding the dynamics of the process, and for interpretation of the results of experiments. As far as we know there are no models available describing the process of $\mathrm{NH}_{3}$ volatilization under field conditions from arable land after application of cattle slurry.

In this paper, we present a transfer model for $\mathrm{NH}_{3}$ volatilization from arable land after surface application or incorporation of cattle slurry. The model can be used to study the interaction of the chemical, physical and environmental factors influencing volatilization losses and their combined influence on $\mathrm{NH}_{3}$ volatilization under field conditions. The work is part of an integrated programme which deals with the chemical, physical and biological aspects of the application of animal manures to soils. The model presented in this paper serves as the base for a predictive $\mathrm{NH}_{3}$ volatilization model.

\section{Model description}

\section{General theory}

Cattle slurry is a mixture of urine and faeces excreted by cattle. Before application to the land, the slurry is kept in storage tanks. During storage, urea, which is a component of urine, undergoes hydrolysis catalysed by urease according to:

$$
\mathrm{CO}\left(\mathrm{NH}_{2}\right)_{2}+2 \mathrm{H}_{2} \mathrm{O} \rightarrow\left(\mathrm{NH}_{4}\right)_{2} \mathrm{CO}_{3} \rightarrow \mathrm{NH}_{3}+\mathrm{NH}_{4}^{+}+\mathrm{HCO}_{3}
$$

It is because of this process that cattle slurry from storage tanks contains ammoniacal $\mathrm{N}$, which may be lost through $\mathrm{NH}_{3}$ volatilization after application to the land. The amount of ammoniacal $\mathrm{N}$ that may volatilize after application strongly depends on the amount being lost while the animals are housed, and during storage and application of the liquid manure.

Volatilization of $\mathrm{NH}_{3}$ after land-application will take place if the $\mathrm{NH}_{3(\mathrm{~g})}$ concentration at the surface exceeds the $\mathrm{NH}_{3(\mathrm{~g})}$ concentration in the air. When the ammonia profile in the air is in equilibrium with the concentration at the surface, the rate of volatilization $R(t)\left(\mu \mathrm{g} \mathrm{N} \mathrm{m}^{-2} \mathrm{~s}^{-1}\right)$ can be expressed as the difference between the $\mathrm{NH}_{3(\mathrm{~g})}$ surface concentration $C_{\mathrm{s}}(t)\left(\mu \mathrm{g} \mathrm{N} \mathrm{m}^{-3}\right)$ and the concentration $C_{\mathrm{a}}(t)(\mu \mathrm{g} \mathrm{N}$ $\mathrm{m}^{-3}$ ) at a specified height $z_{\mathrm{a}}(\mathrm{m})$ above the surface (Rachhpal-Singh \& Nye, 1986):

$$
R(t)=k(t)\left\{C_{\mathrm{s}}(t)-C_{\mathrm{a}}(t)\right\}
$$

where $k(t)\left(\mathrm{m} \mathrm{s}^{-1}\right)$ is a เransfer function. The rate of volatilization $R(t)$ as described by Equation 2 can be calculated at any moment after application when all three terms on the right-hand side of Equation 2 are known at these very moments. The model basically consists of two main modules, which yield $k(t)$ and 
$C_{\mathrm{s}}(t)$, respectively. The atmospheric $\mathrm{NH}_{3(\mathrm{~g})}$ concentration, $C_{\mathrm{a}}(t)$, is required as input for the model.

The transfer module describes the volatilization process itself, i.e. the transfer of $\mathrm{NH}_{3(\mathrm{~g})}$ from the earth's surface into the atmosphere, and yields the transfer function $k(t)$. The description of the transfer function is obtained from the same theory which has been developed for evaporation of water into the atmosphere, but which is sufficiently general to allow description of volatilization of $\mathrm{NH}_{3}$ as well.

In the soil module the magnitude of the $\mathrm{NH}_{3(\mathrm{~g})}$ concentration at the surface, $C_{\mathrm{s}}(t)$, is calculated. In order to determine this concentration, a number of chemical and physical processes which define the distribution of ammoniacal $\mathrm{N}$ over the different phases of the soil/manure system and the transport within the system, have to be taken into account. In addition to $\mathrm{NH}_{3}$ volatilization, other processes may influence the ammoniacal- $\mathrm{N}$ content of the system during a volatilization event. These are biological processes which consume (nitrification, immobilization) or produce (mineralization) ammoniacal N. A more accurate description of the two modules mentioned so far is given below.

\section{Soil module}

The distribution of the ammoniacal $\mathrm{N}$, applied with slurry, immediately after application depends on the method of application. In case of surface application, slurry is spread on the land after which the slurry infiltrates into the soil, whereas in case of incorporation the slurry is mixed through the upper layer of soil after spreading. For both surface application and incorporation, the initial distribution of the ammoniacal $\mathrm{N}$ is assumed to be uniform down to a certain depth. The difference between the two application techniques appears in the depth over which the ammoniacal $\mathrm{N}$ is initially distributed. This depth, $L_{\text {init }}(\mathrm{m})$, is selected to reflect the principal extent of cattle slurry placement, i.e. in case of surface application the effective distance over which infiltration occurs, and in case of incorporation the thickness of the soil layer which the slurry is mixed through. The assumption of a uniform initial ammoniacal-N distribution with depth down to depth $L_{\text {init }}$ implies that, in case of surface application, infiltration of slurry takes place instantaneously.

For the purpose of modelling, the ammoniacal- $\mathrm{N}$ content at the soil surface is assumed to be uniform to some fixed depth, $L_{1}(\mathrm{~m})$. Thus, throughout a top compartment the temporal variations in ammoniacal- $\mathrm{N}$ content resulting from volatilization and chemical, physical or biological processes in the soil are assumed to be uniform. Below this depth, a second compartment of variable thickness $L_{2}(t)(\mathrm{m})$ is assumed from which no volatilization takes place. This compartment acts as a storage reservoir for the amount of ammoniacal $\mathrm{N}$ originating from the slurry that is placed below depth $L_{1}$. The front of the ammoniacal- $N$ content profile in the soil coincides with the bottom of this compartment at a depth $L(t)(\mathrm{m})$, where a stepchange in ammoniacal- $\mathrm{N}$ content occurs. Within this compartment the distribution of the ammoniacal $\mathrm{N}$ present and the temporal variations in ammoniacal- $\mathrm{N}$ content due to chemical, physical or biological processes are also assumed to be uniform with depth. 
As the initial distribution of the ammoniacal $\mathrm{N}$ is assumed to be uniform down to depth $L_{\text {init }}$, the amounts of ammoniacal $\mathrm{N}$ initially stored in the two compartments, $\mathrm{NH}_{x 1, \mathrm{i}}$ and $\mathrm{NH}_{x 2, \mathrm{i}}$ (both in $\mu \mathrm{g} \mathrm{N} \mathrm{m}^{-2}$ ), are defined by the total amount of ammoniacal $\mathrm{N}$ applied with the slurry, $\mathrm{NH}_{x \text {,app }}\left(\mu \mathrm{g} \mathrm{N} \mathrm{m}^{-2}\right)$, the depth $L_{\text {init }}$ over which this ammoniacal $\mathrm{N}$ is placed initially and the thickness $L_{1}$ of the top compartment $\left(L_{1}\right.$ is a fixed value for a certain type of application; its magnitude is obtained from calibration of the model). The model therefore requires $\mathrm{NH}_{x, \text { app }}, L_{\text {init }}$ and $L_{1}$ as input, and calculates $\mathrm{NH}_{x 1, \mathrm{i}}, \mathrm{NH}_{x 2, \mathrm{i}}$ and the initial value of $L_{2}(t), L_{2, \mathrm{i}}$, as follows:

$$
\begin{aligned}
& L_{2, \mathrm{i}}=L_{\text {init }}-L_{1} \\
& \mathrm{NH}_{x 1, \mathrm{i}}=\mathrm{NH}_{x, \mathrm{app}} \times L_{1} / L_{\text {init }} \\
& \mathrm{NH}_{x 2, \mathrm{i}}=\mathrm{NH}_{x, \mathrm{app}} \times L_{2, \mathrm{i}} / L_{\text {init }}
\end{aligned}
$$

Figure 1 gives a schematic representation of the distribution of the total amount of ammoniacal $\mathrm{N}$ originating from the slurry immediately after application.

The volumetric flux of water, $J_{\mathrm{w}}(t)\left(\mathrm{m} \mathrm{s}^{-1}\right)$, through the two compartments, which is assumed to be constant with depth, is calculated from the net difference between the evaporation rate, $E(t)\left(\mathrm{m} \mathrm{s}^{-1}\right)$, and the rainfall rate, $P(t)\left(\mathrm{m} \mathrm{s}^{-1}\right)$, i.e.:

$$
J_{\mathrm{w}}(t)=E(t)-P(t)
$$

In order to calculate $J_{\mathrm{w}}(t)$ throughout a volatilization event from Equation 5, data on evaporation and rainfall rates throughout the event are required as input.

The flux of ammoniacal $\mathrm{N}$ between the two compartments is assumed to take place by convective transport in the liquid phase and diffusive transport in both the liquid and the gas phase.
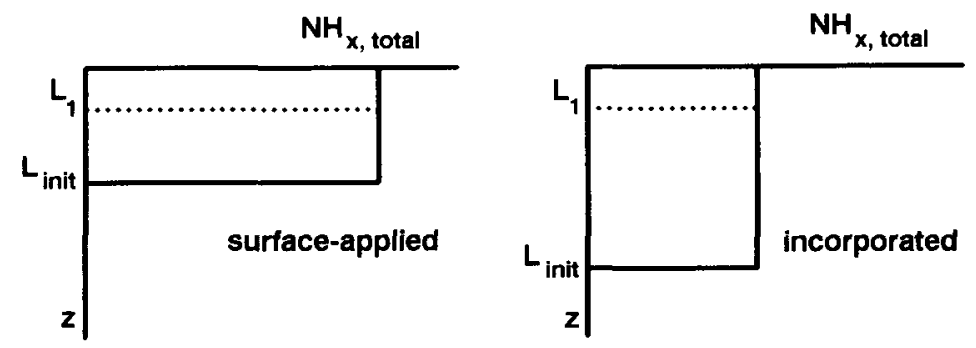

Fig. 1. Schematic representation of the initial distribution of the total amount of ammonical N originating from the slurry following surface application and following incorporation of the same amounts of slurry. 
Convective transport, $J_{\mathrm{c}}(t)\left(\mu \mathrm{g} \mathrm{N} \mathrm{m} \mathrm{N}^{-2} \mathrm{~s}^{-1}\right)$, is calculated as:

$$
J_{\mathrm{c}}(t)=J_{\mathrm{w}}(t) \times\left(\left[\mathrm{NH}_{3}\right]_{\mathrm{aq}}+\left[\mathrm{NH}_{4}\right]_{\mathrm{aq}}\right)
$$

where $\left[\mathrm{NH}_{3}\right]_{\mathrm{aq}}$ and $\left[\mathrm{NH}_{4}{ }^{+}\right]_{\mathrm{aq}}$ are the concentrations $\left(\mu \mathrm{g} \mathrm{N} \mathrm{m}{ }^{-3}\right)$ of $\mathrm{NH}_{3}$ and $\mathrm{NH}_{4}{ }^{+}$ in solution. Ammoniacal $\mathrm{N}$ is transported from the bottom compartment to the top compartment if the net water flux is in the upward direction, $E(t)>P(t)$, whereas transport of ammoniacal $\mathrm{N}$ from the top compartment to the bottom compartment takes place in case of a downward net water flux, $E(t)<P(t)$. The way $\left[\mathrm{NH}_{3}\right]_{\mathrm{aq}}$ and $\left[\mathrm{NH}_{4}{ }^{+}\right]_{\mathrm{aq}}$ are calculated is shown below.

Diffusive transport, $J_{\mathrm{d}}(t)\left(\mu \mathrm{g} \mathrm{N} \mathrm{m} \mathrm{m}^{-2} \mathrm{~s}^{-1}\right)$, is calculated as:

$$
J_{\mathrm{d}}(t)=J_{\mathrm{dg}}(t)+J_{\mathrm{daq} 1}(t)+J_{\mathrm{daq} 2}(t)
$$

where subscripts $\mathrm{g}$ and aq denote gaseous and aqueous, respectively; the terms on the right-hand side are calculated as:

$$
\begin{aligned}
& J_{\mathrm{dg}}(t)=-D_{\mathrm{g}} \times\left(\left[\mathrm{NH}_{3}\right]_{\mathrm{g} 1}-\left[\mathrm{NH}_{3}\right]_{\mathrm{g} 2}\right) \times L_{\mathrm{d}}{ }^{-1} \\
& J_{\mathrm{daq} 1}(t)=-D_{\mathrm{aq}} \times\left(\left[\mathrm{NH}_{3}\right]_{\mathrm{aq} 1}-\left[\mathrm{NH}_{3}\right]_{\mathrm{aq} 2}\right) \times L_{\mathrm{d}}{ }^{-1} \\
& J_{\mathrm{daq} 2}(t)=-D_{\mathrm{aq}} \times\left(\left[\mathrm{NH}_{4}\right]_{\mathrm{aq} 1}-\left[\mathrm{NH}_{4}{ }^{+}\right]_{\mathrm{aq} 2}\right) \times L_{\mathrm{d}}{ }^{-1}
\end{aligned}
$$

The subscripts 1 and 2 on the right-hand side refer to the compartment number. The terms $D_{\mathrm{g}}$ and $D_{\mathrm{aq}}$ denote the gaseous and aqueous diffusion coefficient, respectively, and are derived below. The diffusion length, $L_{\mathrm{d}}$, is calculated as: $L_{\mathrm{d}}=\left\{L_{1}+\right.$ $\left.L_{2}(t)\right\} \times 0.5$.

As mentioned earlier, the thickness of the top compartment, $L_{1}$, is fixed for a volatilization event, whereas the thickness of the bottom compartment, $L_{2}(t)$, may deviate from its initial value, $L_{2, \mathrm{i}}$. By definition the bottom compartment at $t=0$ contains all ammoniacal $\mathrm{N}$ originating from the slurry that is placed below depth $L_{1}$; it is assumed that the soil initially did not contain ammoniacal $N$. The lower boundary of this compartment coincides with the front of the ammoniacal- $\mathrm{N}$ content profile in the soil at a depth $L(t)$, where a step-change in ammoniacal- $\mathrm{N}$ content occurs. In order to keep track of the thickness of the bottom compartment, $L_{2}(t)$, the model calculates the rate $J_{s}(t)\left(\mathrm{m} \mathrm{s}^{-1}\right)$, at which the ammoniacal-N front moves through the soil for $t>0$ :

$$
J_{\mathrm{s}}(t)=\frac{J_{\mathrm{w}}(t)}{\theta_{\nu}(t)}\left(\frac{1}{1+R_{D}}\right)
$$

where $R_{D}(-)$ is the retardation factor for the transport of $\mathrm{NH}_{4}^{+}$(Equation 21), and $\theta_{\mathrm{v}}(t)$ is the volumetric water content (required as input). The model calculates 
the thickness of the bottom compartment, $L_{2}(t)$, after each time step according to:

$$
L_{2}(t)=L_{2}\left(t^{\prime}\right)-J_{\mathrm{s}}(t) \times \Delta t
$$

where $\Delta t$ is the current time step (s) and $L_{2}\left(t^{\prime}\right)$ is the thickness of the bottom compartment prior to the time step.

The amounts of ammoniacal $\mathrm{N}$ present in the two compartments, $\mathrm{NH}_{x 1}(t)$ and $\mathrm{NH}_{x 2}(t)$ (both in $\mu \mathrm{g} \mathrm{N} \mathrm{m}^{-2}$ ), for $t>0$, are calculated according to:

$$
\begin{aligned}
& \mathrm{NH}_{x 1}(t)=\mathrm{NH}_{x 1}\left(t^{\prime}\right)-S_{1}+I-V \\
& \mathrm{NH}_{x 2}(t)=\mathrm{NH}_{x 2}\left(t^{\prime}\right)-S_{2}-I
\end{aligned}
$$

where the prime denotes the amount of ammoniacal $\mathrm{N}$ present prior to the time step; $S, I$ and $V\left(\mu \mathrm{g} \mathrm{N} \mathrm{m}^{-2}\right)$ are a sink term representing the net loss due to biological processes, the net inflow of ammoniacal $\mathrm{N}$ due to convective and diffusive transport and the amount of ammoniacal $\mathrm{N}$ volatilized, respectively. The magnitude of the terms $V, I$ and $S$ in Equations $11 \mathrm{a}$ and $11 \mathrm{~b}$ is calculated from the current time step, $\Delta t$, and the rates at which volatilization (Equation 2), inflow of ammoniacal $\mathrm{N}$ (Equations 6 and 7) and net loss of ammoniacal $\mathrm{N}$ due to biological processes, $s(t)$ $\left(\mu \mathrm{g} \mathrm{N} \mathrm{m}^{-2} \mathrm{~s}^{-1}\right)$, occur:

$$
\begin{aligned}
& V=R(t) \times \Delta t \\
& I=\left\{J_{\mathrm{c}}(t)+J_{\mathrm{d}}(t)\right\} \times \Delta t \\
& S_{1}=s_{1}(t) \times \Delta t, \quad S_{2}=s_{2}(t) \times \Delta t
\end{aligned}
$$

Data on the rate, $s(t)$, at which net loss of ammoniacal $\mathrm{N}$ from the system due to biological processes takes place are part of the input for the model. The distribution of the rate $s(t)$ over the compartments is carried out according to:

$$
\begin{aligned}
. s_{1}(t) & =s(t) \frac{\mathrm{NH}_{x 1}(t)}{\mathrm{NH}_{x 1}(t)+\mathrm{NH}_{x 2}(t)} \\
s_{2}(t) & =s(t) \frac{\mathrm{NH}_{x 2}(t)}{\mathrm{NH}_{x 1}(t)+\mathrm{NH}_{x 2}(t)}
\end{aligned}
$$

The distribution of the amounts of ammoniacal $\mathrm{N}$ present in each compartment over the different phases in the soils is calculated from the amount of ammoniacal $\mathrm{N}$ present in each compartment, $\mathrm{NH}_{x 1}(t)$ and $\mathrm{NH}_{x 2}(t)$, and relationships between the concentrations of the different ammoniacal species. $\mathrm{NH}_{x 1}(t)$ and $\mathrm{NH}_{x 2}(t)$ can be expressed in terms of the concentrations of the different ammoniacal species as follows: 


$$
\begin{aligned}
& \mathrm{NH}_{x 1}(t)=L_{1}\left(\theta_{\mathrm{g}}\left[\mathrm{NH}_{3}\right]_{\mathrm{g}, 1}+\theta_{\mathrm{v}}\left[\mathrm{NH}_{3}\right]_{\mathrm{aq}, 1}+\theta_{\mathrm{v}}\left[\mathrm{NH}_{4}{ }^{+}\right]_{\mathrm{aq}, 1}+\varrho_{\mathrm{b}}\left[\mathrm{NH}_{4}{ }^{+}\right]_{\mathrm{s}, 1}\right)(17) \\
& \mathrm{NH}_{x 2}(t)=L_{2}(t)\left(\theta_{\mathrm{g}}\left[\mathrm{NH}_{3}\right]_{\mathrm{g}, 2}+\theta_{\mathrm{v}}\left[\mathrm{NH}_{3}\right]_{\mathrm{aq}, 2}+\theta_{\mathrm{v}}\left[\mathrm{NH}_{4}{ }^{+}\right]_{\mathrm{aq}, 2}+\varrho_{\mathrm{b}}\left[\mathrm{NH}_{4}{ }^{+}\right]_{\mathrm{s}, 2}\right)(18)
\end{aligned}
$$

where the subscripts $\mathrm{g}$, aq and $\mathrm{s}$ denote concentrations in the soil gaseous phase ( $\mu \mathrm{g}$ $\left.\mathrm{N} \mathrm{m}^{-3}\right)$, the soil aqueous phase $\left(\mu \mathrm{g} \mathrm{N} \mathrm{m}^{-3}\right)$ and the soil solid phase $(\mu \mathrm{g} \mathrm{N}$ per $\mathrm{kg}$ of dry soil material) respectively; $\varrho_{b}$ is the dry bulk density of the soil $\left(\mathrm{kg} \mathrm{m}^{-3}\right)$ and $\theta_{\mathrm{g}}$ is the gas-filled pore volume $(-)$, which is calculated from the porosity, $\phi(-)$, and the volumetric water content $\theta_{\mathrm{v}}$ according to:

$$
\theta_{\mathrm{g}}=\phi-\theta_{\mathrm{v}}
$$

Both $\phi$ and $\varrho_{\mathrm{b}}$ are required as input for the model.

With $\mathrm{NH}_{x 1}(t)$ and $\mathrm{NH}_{x 2}(t)$ known from Equations 11a and $11 \mathrm{~b}, L_{1}$ obtained from calibration of the model, $L_{2}(t)$ and $\theta_{\mathrm{g}}$ defined by Equations 10 and 19 and $\theta_{\mathrm{v}}$ and $\varrho_{b}$ given with the input, the concentrations on the right-hand sides of Equations 17 and 18 are calculated with the help of the following relationships between the concentrations of the different ammoniacal species.

The partitioning of $\mathrm{NH}_{4}+$ between the soil solid and the soil aqueous phases is optionally described by a linear isotherm (Equation 20a), a Freundlich isotherm (Equation 20b), or a Langmuir isotherm (Equation 20c):

$$
\begin{aligned}
& {\left[\mathrm{NH}_{4}{ }^{+}\right]_{\mathrm{s}}=a\left[\mathrm{NH}_{4}{ }^{+}\right]_{\mathrm{aq}}} \\
& {\left[\mathrm{NH}_{4}{ }^{+}\right]_{\mathrm{s}}=a\left(\left[\mathrm{NH}_{4}{ }^{+}\right]_{\mathrm{aq}}\right)^{\prime}} \\
& {\left[\mathrm{NH}_{4}{ }^{+}\right]_{\mathrm{s}}=\frac{a b\left[\mathrm{NH}_{4}{ }^{+}\right]_{\mathrm{aq}}}{1+b\left[\mathrm{NH}_{4}{ }^{+}\right]_{\mathrm{aq}}}}
\end{aligned}
$$

where $\left[\mathrm{NH}_{4}{ }^{+}\right]_{\mathrm{aq}}$ and $\left[\mathrm{NH}_{4}{ }^{+}\right]_{5}$ are again given in $\left(\mu \mathrm{g} \mathrm{N} \mathrm{m}^{-3}\right)$ and $(\mu \mathrm{g} \mathrm{N}$ per kg of dry soil material) respectively; $a$ and $b$ are constants, which are input parameters for the model.

The retardation factor $R_{D}$ (Equation 9), which is defined as the ratio between the amount of $\mathrm{NH}_{4}{ }^{+}$adsorbed by the soil solid phase and the amount of $\mathrm{NH}_{4}+$ in solution (Bolt, 1976), is calculated from:

$$
R_{D}=\frac{\varrho_{\mathrm{b}}\left[\mathrm{NH}_{4}{ }^{+}\right]_{\mathrm{s}}}{\theta_{\mathrm{v}}\left[\mathrm{NH}_{4}{ }^{+}\right]_{\mathrm{aq}}}
$$

The relation between $\mathrm{NH}_{4}{ }^{+}$and $\mathrm{NH}_{3}$ in solution is calculated from the equilibrium constant $K_{\mathrm{a}}\left(\mathrm{mol} \mathrm{1}^{-1}\right)$ for the dissociation of $\mathrm{NH}_{4}{ }^{+}{ }_{\text {(aq) }}$ :

$$
\begin{aligned}
& \mathrm{NH}_{4}{ }^{+}{ }_{\text {(aq) }}+\mathrm{H}_{2} \mathrm{O}-\mathrm{NH}_{3 \text { (aq) }}+\mathrm{H}_{3} \mathrm{O}^{+}{ }_{\text {(aq) }} \\
& \frac{\left[\mathrm{NH}_{3}\right]_{\mathrm{aq}}}{\left[\mathrm{NH}_{4}{ }^{+}\right]_{\mathrm{aq}}}=\frac{K_{a}}{\left[\mathrm{H}_{3} \mathrm{O}^{+}\right]}
\end{aligned}
$$


where $K_{\mathrm{a}}$ is calculated from (Hales \& Drewes, 1979):

$$
\log K_{\mathrm{a}}=-0.09018-2729.92 T^{-1}
$$

and:

$$
\left[\mathrm{H}_{3} \mathrm{O}^{+}\right]_{\mathrm{aq}}=10^{-\mathrm{pH}}
$$

where $\left[\mathrm{H}_{3} \mathrm{O}^{+}\right]_{\mathrm{aq}}$ is expressed in $\left(\mathrm{mol} \mathrm{l} \mathrm{I}^{-1}\right)$. In order to calculate $K_{\mathrm{a}}$ and $\left[\mathrm{H}_{3} \mathrm{O}^{+}\right]_{\text {aq }}$ from Equations 24 and 25, data on soil temperature $(\mathrm{K})$ and $\mathrm{pH}$ are required as input.

The ratio between $\mathrm{NH}_{3}$ in the soil solution and the soil gaseous phase is calculated from Henry's law:

$$
K_{\mathrm{h}}=\left[\mathrm{NH}_{3}\right]_{\mathrm{aq}} /\left[\mathrm{NH}_{3}\right]_{\mathrm{g}}
$$

where Henry's law equilibrium constant $(-)$ is given by (Hales \& Drewes, 1979):

$$
\log K_{\mathrm{h}}=-1.69+1477.7 T^{-1}
$$

in which $T$ is again the absolute soil temperature $(\mathrm{K})$.

Now when all the concentrations on the right-hand-sides of Equations 17 and 18 are known, the description of the soil module has been completed. From the definition of the top compartment, i.e. a uniform ammoniacal-N content distribution from the soil surface down to $L_{1}$, and the use of constant $\theta_{\mathrm{g}}, \theta_{\mathrm{v}}$ and $\varrho_{\mathrm{b}}$ from the soil surface down to $L(t)$ during a volatilization event, it follows that $\left[\mathrm{NH}_{3}\right]_{\mathrm{g}}$ equals $C_{\mathrm{s}}(t)$ (Equation 2). With $C_{\mathrm{s}}(t)$ known from the soil module and $C_{\mathrm{a}}(t)$ given as input, only the transfer function $k(t)$ has to be defined to complete Equation 2 for operation.

\section{Transfer module}

As mentioned earlier, volatilization of $\mathrm{NH}_{3}$ after land-application will take place if the $\mathrm{NH}_{3(\mathrm{~g})}$ concentration at the surface exceeds the $\mathrm{NH}_{3(\mathrm{~g})}$ concentration in the air. When the ammonia profile in the air is in equilibrium with the concentration at the surface, the rate of volatilization $R(t)$ can be expressed as the difference between the $\mathrm{NH}_{3(\mathrm{~g})}$ surface concentration $C_{\mathrm{s}}(t)$ and the concentration $C_{\mathrm{a}}(t)$ at a specified height $z_{\mathrm{a}}$ above the surface as described by Equation 2:

$$
R(t)=k(t)\left\{C_{\mathrm{s}}(t)-C_{\mathrm{a}}(t)\right\}
$$

where $k(t)$ is a transfer function, which is defined by:

$$
k(t)=\frac{1}{r_{\mathrm{a}}(x, t)+r_{\mathrm{b}}(t)+r_{\mathrm{s}}(t)}
$$




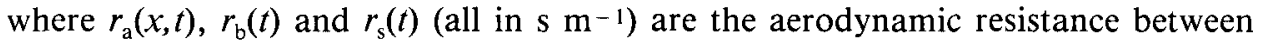
height $z_{\mathrm{a}}$ and the surface, the resistance of the interfacial sublayer and the surface resistance respectively. The aerodynamic resistance represents the resistance of the turbulent layer between height $z_{\mathrm{a}}$ (e.g. observation height) and $z=z_{\mathrm{o}}$, where $z_{\mathrm{o}}$ is the aerodynamic roughness length of the surface $(\mathrm{m})$. The roughness length $z_{\mathrm{o}}$ ranges from $1 \mathrm{~mm}$ for smooth bare soil to $1 \mathrm{~m}$ for a surface with tall vegetation (e.g. trees; see Wieringa, 1986, for the relation between $z_{0}$ and terrain characteristics). The resistance of the interfacial sublayer represents the additional resistance for passive contaminants due to molecular diffusion, which is not present in the case of momentum transfer (e.g. Brutsaert, 1982). The surface resistance represents the resistance of the surface itself and is the result of the diffusion processes from inside the soil/slurry layer towards the air.

In the case of a manured field of limited size, the surface emission is not in equilibrium with the concentration profile and advection plays a dominant role. As schematically shown in Figure 2 an internal boundary layer develops over the manured field. The internal boundary layer depth is a measure for the height over which the volatilization of the manured field is felt.

To model the volatilization rate $R(t)$ of the manured field we want to relate the difference between the surface concentration $C_{s}(t)$ and the background concentration $C_{\mathrm{a}}(t)$ of the air advected from upstream. This means that we have to estimate the resistance introduced in Equation 28. This is an inhomogeneous diffusion problem with a sudden downstream transition in the surface concentration. The wind forcing remains unchanged because the aerodynamic characteristics of the surface are not altered.

In order to calculate the aerodynamic resistance $r_{\mathrm{a}}(x, t)$, an approximate expression for the depth $l(\mathrm{~m})$ of the internal boundary layer in neutral flow conditions (Townsend, 1965; Blom \& Wartena, 1969) is used:

$$
l\left\{\ln \left(l / z_{\mathrm{o}}\right)-1\right\}=\varkappa^{2} x
$$

where $x(\mathrm{~m})$ is the distance from the leading edge of the manured field measured

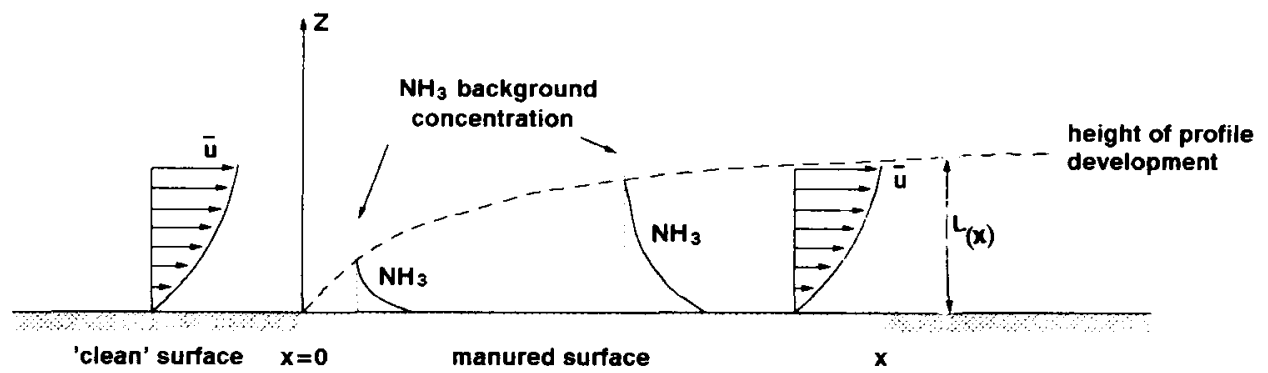

Fig. 2. Schematic representation of the development of the concentration profile of $\mathrm{NH}_{3(\mathrm{~g})}$ over the manured field (adapted from Brutsaert, 1982). 
in the direction of the mean wind and $\varkappa$ the von Karman constant $(\varkappa=0.4(-))$. It is known from internal boundary layer studies (e.g. Elliott, 1958; Jensen et al., 1984; Taylor \& Lee, 1984; see Pasquill, 1972, for the analogy between diffusion of pollutants and internal boundary layer growth) that in neutral situations the wind profile inside the internal boundary layer is reasonably well approximated by the logarithmic form that satisfies the appropriate surface condition and the background concentration at $z=l$. For the aerodynamic resistance this implies:

$$
r_{\mathrm{a}}(x, t)=\ln \left(l / z_{\mathrm{o}}\right) /\left\{\varkappa \times u_{*}(t)\right\}
$$

where $u_{*}(t)$ is the friction velocity i.e. the scaling velocity of the logarithmic wind profile (see Appendix for the relation between $u_{*}(t)$ and the wind profile). Since $l$ increases with $x, r_{\mathrm{a}}(x, t)$ increases also resulting in a decreasing volatilization rate $R(t)$ as a function of $x$. The volatilization rate $R(t)$ averaged over the field can be obtained by vertical integration of the net outflow $\left(\int U\left(C-C_{\mathrm{a}}\right) \mathrm{d} z\right.$ with $U$ for wind speed) at the downstream edge of the field. Since $R(t)$ decreases only slowly with $x$, a reasonable approximation is obtained by choosing $r_{\mathrm{a}}(x, t)$ and $l$ at the downstream end of the field for the computation of the field averaged $r_{\mathrm{a}}(x, t)$ and $R(t)$. From $x=2.5 \mathrm{~m}$ to $x=24 \mathrm{~m}$ the resistance changes by no more than $25 \%$. Near the leading edge the errors are larger but in this area we cannot expect high accuracy because the assumption that $l / x$ is small breaks down. In order to calculate $r_{\mathrm{a}}\left(L_{x}, t\right)$ with $L_{x}$ as length of the field, from Equations 29 and $30, L_{x}, z_{\mathrm{o}}$ and $u_{*}$ are required as input for the model.

It should be noted that the expressions above refer to neutral atmospheric flow in the surface layer. According to Monin-Obukhov similarity theory (e.g. Stull, 1988), this implies that $l /|L|$ should be much smaller than 1 , where $L$ (m) stands for the Obukhov length. For an experimental field with a length $L_{x}$ of $21.25 \mathrm{~m}$ (which was used to test the model), the internal boundary layer height $l$ is $0.96 \mathrm{~m}$ at the downstream edge. This internal boundary layer is extremely shallow which justifies the neutral approximation because $|L|$ is often larger than $5 \mathrm{~m}$ (except in cases with hardly any wind). However, to derive $u_{*}(t)$ from wind observations at 10 $m$ height it is often necessary to apply stability corrections to the logarithmic profile (see Appendix). For large fields and for very low wind speeds it might be necessary to apply stability corrections to the expressions for $l, r_{\mathrm{a}}(x, t)$ and $R(t)$ (see the Appendix for the appropriate expressions and for a more extensive discussion on stability effects).

Hardly any information exists on the value of the resistance $r_{\mathrm{b}}(t)$ of the quasilaminar layer for $\mathrm{NH}_{3(\mathrm{~g})}$. There is no reason to believe however that the behaviour of $\mathrm{NH}_{3(\mathrm{~g})}$ near the surface is different from other passive substances as water vapor and heat. The parameter $r_{\mathrm{b}}(t)$ is often specified by means of the integration constant $z_{\mathrm{oc}}$ (roughness length for concentration $(\mathrm{m})$ ) in the concentration profile. Brutsaert (1982) reviews data and theoretical values and concludes that $z_{\mathrm{o}} / z_{\mathrm{oc}}$ is about 10, which means that:

$$
r_{\mathrm{b}}(t)=\ln \left(z_{\mathrm{o}} / z_{\mathrm{oc}}\right) /\left\{x \times u_{*}(t)\right\} \sim 5.8 / u_{*}(t)
$$

The surface resistance $r_{s}(t)$ represents the resistance of the surface itself and is the 
result of the diffusion processes from inside the soil/slurry layer towards the air. The diffusion rate $J_{D}(t)\left(\mu \mathrm{g} \mathrm{N} \mathrm{m}^{-2} \mathrm{~s}^{-1}\right)$ is defined by:

$$
J_{D}(t)=D_{\mathrm{aq}} \frac{\left(\bar{C}_{\mathrm{aq}}-C_{\mathrm{aq}, \mathrm{s}}\right)}{l_{\mathrm{c}}}+D_{\mathrm{g}} \frac{\left(\bar{C}_{\mathrm{g}}-C_{\mathrm{g}, \mathrm{s}}\right)}{l_{\mathrm{c}}}
$$

where $\bar{C}_{\mathrm{aq}}$ and $\bar{C}_{\mathrm{g}}$ are the average concentrations of ammoniacal $\mathrm{N}$ in the aqueous and the gaseous phase in the soil, respectively; $C_{\mathrm{aq}, \mathrm{s}}$ and $C_{\mathrm{g}, \mathrm{s}}$ are the ammoniacal-N concentrations in the same phases at the soil surface; $l_{\mathrm{c}}$ is the average distance $(\mathrm{m})$ which the ammoniacal $\mathrm{N}$ has to bridge over to reach the surface $\left(=0.5 L_{l} ; D_{\text {aq }}\right.$ and $D_{\mathrm{g}}$ are the soil-liquid and the soil-gas diffusion coefficients for ammoniacal $\mathrm{N}$. Note that the soil-liquid diffusion coefficient is assumed to be the same for $\mathrm{NH}_{3}$ and $\mathrm{NH}_{4}{ }^{+}$. Substitution of Henry's law (Equation 26) in Equation 32 yields:

$$
J_{D}(t)=D_{\mathrm{aq}} K_{\mathrm{h}} \frac{\left(\bar{C}_{\mathrm{g}}-C_{\mathrm{g}, \mathrm{s}}\right)}{l_{\mathrm{c}}}+D_{\mathrm{g}} \frac{\left(\bar{C}_{\mathrm{g}}-C_{\mathrm{g}, \mathrm{s}}\right)}{l_{\mathrm{c}}}
$$

or

$$
J_{D}(t)=\left(D_{\mathrm{aq}} K_{\mathrm{h}}+D_{\mathrm{g}}\right) \frac{\left(\bar{C}_{\mathrm{g}}-C_{\mathrm{g}, \mathrm{s}}\right)}{l_{\mathrm{c}}}
$$

where $\bar{C}_{\mathrm{g}}$ equals $C_{\mathrm{s}}(t)$ from Equation 2 .

From the definition of $r_{\mathrm{s}}(t)$ it follows that the diffusion rate $J_{D}(t)$ as expressed by Equation 34 can also be written as:

$$
J_{D}(t)=\frac{1}{r_{\mathrm{s}}(t)}\left(\bar{C}_{\mathrm{g}}-C_{\mathrm{g}, \mathrm{s}}\right)
$$

Combination of Equations 34 and 35 yields the following expression for $r_{\mathrm{s}}(t)$ :

$$
r_{\mathrm{s}}(t)=\frac{0.5 L_{1}}{D_{\mathrm{aq}} K_{\mathrm{h}}+D_{\mathrm{g}}}
$$

where $0.5 L_{l}$ has been substituted for $l_{c}$, the average distance over which the ammoniacal $\mathrm{N}$ in the top compartment has to be transported to reach the soil surface. Henry's law constant $K_{\mathrm{h}}$ is calculated from Equation 27. The soil-liquid and the soil-gas diffusion coefficients are equalled to the water-liquid and the air-gas diffusion coefficient by multiplying by tortuosity factors to account for the reduced flow area and increased path length of diffusing ammoniacal $\mathrm{N}$ in soil. The tortuosity factors, which are functions of the volumetric moisture content, respectively the gas-filled pore volume, and the soil geometry, are described by the Millington-Quirk model (Jury et al., 1983). With this model we obtain the following expressions:

$$
\begin{aligned}
& D_{\mathrm{aq}}=\left(\theta_{\mathrm{v}} 10 / 3 / \phi^{2}\right) D_{\mathrm{aq}}^{\text {water }} \\
& D_{\mathrm{g}}=\left(\theta_{\mathrm{g}}{ }^{10 / 3} / \phi^{2}\right) D_{\mathrm{g}}^{\text {air }}
\end{aligned}
$$

where $D_{\mathrm{aq}}^{\text {water }}$ and $D_{\mathrm{g}}^{\text {air }}$ are the water-liquid and the air-gas diffusion coefficients (m² $\mathrm{s}^{-1}$ ) and $\theta_{\mathrm{v}}, \theta_{\mathrm{g}}$ and $\phi$ are the volumetric moisture content, the gas-filled pore volume and the porosity. Tabulated values of the water-liquid diffusion coefficient 
as a function of temperature are given by Yuan-Hui \& Gregory (1974); from these data the following expression was derived:

$$
D_{\mathrm{aq}}^{\text {water }}=9.8 \times 10^{-10} \times 1.03^{(T-273)}
$$

where $T$ is the absolute temperature (K). A similar expression for the temperaturedependence of the air-gas diffusion coefficient was derived from the work of Bruckler et al. (1989):

$$
D_{\mathrm{g}}^{\mathrm{air}}=1.7 \times 10^{-5} \times 1.03^{(T-293)}
$$

In order to calculate $r_{\mathrm{s}}(t)$ from Equations $36-40 \theta_{\mathrm{v}}, \phi$ and $T$ are required as input for the model.

With the above expressions for $r_{\mathrm{a}}(x, t), r_{\mathrm{b}}(t)$ and $r_{\mathrm{s}}(t)$, the description of the transfer function $k(t)$ (Equation 28), in case of a field of limited size, is complete.

The computer program of the whole model was written in FORTRAN 77; it can be used on a VAX main frame and on a $640 \mathrm{~K}$ IBM-compatible PC. A listing of the program is available from the third author.

\section{Summary and conclusions}

This paper presents a transfer model for $\mathrm{NH}_{3}$ volatilization from slurry. The model can be used to study the interaction of the chemical, physical and environmental factors influencing volatilization losses and their combined influence on $\mathrm{NH}_{3}$ volatilization under field conditions.

The model requires the following set of input data: the amount of ammoniacal $\mathrm{N}$ applied with the slurry and the initial depth of ammoniacal- $\mathrm{N}$ placement in the soil, the atmospheric $\mathrm{NH}_{3}$ background concentration, the type of adsorption isotherm to be used and the related constants, the aerodynamic roughness length of the surface, the distance from the leading edge of the manured field measured in the direction of the mean wind (the fetch), time-average values of bulk density and porosity of the top layer, time-dependent values of volumetric moisture content, friction velocity, soil temperature, $\mathrm{pH}$, rainfall rate, evaporation rate and rate of net loss of ammoniacal $\mathrm{N}$ due to biological processes. The thickness of the top compartment has to be obtained from calibration of the model.

A third paper in this series about the experimental verification of the model is prepared by Chardon et al. As mentioned in the introduction, the model serves as the base for a predictive $\mathrm{NH}_{3}$ volatilization model. In order to proceed towards a predictive model the present model has to be extended to be able to predict the $\mathrm{pH}$ and the occurrence of biological processes (nitrification/denitrification, plant uptake) during a volatilization event.

\section{Acknowledgement}

Part of the project was financed by the Dutch Priority Programme on Acidification. 


\section{Appendix}

To solve the internal boundary layer problem for the emission of $\mathrm{NH}_{3}$ from a manured field we have to solve the Equation that describes the balance between horizontal advection and vertical diffusion (this is an alternative to the more complicated trajectory-simulation model by Wilson et al., 1982):

$$
U \frac{\partial C}{\partial x}=\frac{\partial}{\partial z} K \frac{\partial C}{\partial z}
$$

where $C$ is the concentration, $U$ the wind speed as a function of height $z, x$ the downstream distance from the leading edge of the field and $K$ the diffusion coefficient as a function of $z$. The boundary conditions are:

$$
\begin{aligned}
& C=C_{\mathrm{a}} \quad \text { for } x<0 \text { and } z \rightarrow \infty \\
& C=C_{\mathrm{o}} \quad \text { for } x>0 \text { and } z=z_{\mathrm{o}} \\
& \text { with } C_{\mathrm{o}}=C_{\mathrm{s}}-\mathrm{R} \times\left(r_{\mathrm{b}}+r_{\mathrm{s}}\right)
\end{aligned}
$$

This problem can be solved to a reasonable degree of accuracy by assuming that a similarity solution exists. This means that the profile of $C$ keeps the same form but that the scaling depends on $x$. The solution is assumed to be of the form:

$$
\frac{C-C_{\mathrm{a}}}{C_{\mathrm{o}}-C_{\mathrm{a}}}=\mathrm{f}\left(\frac{z}{l}\right)
$$

where $l$ is the internal boundary layer height. Scaling parameters $C_{\mathrm{o}}$ and $l$ both vary with $x$, whereas $\mathrm{f}$ is a function of $z / l$ only. This approach has been used by Townsend (1965) for the step in roughness and the step in surface temperature problems. A double step solution was computed by Blom \& Wartena (1969). It has become recognized however, that the simple logarithmic interpolation between the new surface condition and the upstream value at $z=l$ is almost as accurate as the similarity solution by Townsend (see Jensen et al., (1984) and Taylor \& Lee (1984) for a discussion in the framework of wind energy applications). Since the simple empirical approach can easily be extended to non-neutral conditions we will employ it here instead of an explicit solution of Equation A.1.

The method, originally proposed by Elliott (1958) consists of the computation of an internal boundary layer height $l$ as a function of $x$ and the interpolation between the surface and the background concentration $C_{\mathrm{a}}$ at $z=l$ with help of the profile functions that apply to homogeneous terrain (i.e. with stability correction functions added to the logarithmic form).

To compute the growth of the internal boundary layer we use the analogy as described by Pasquill (1972) between vertical diffusion of pollutants and internal boundary layer growth. The resulting expression reads (see van Ulden, 1978; van Wijk et al., 1989):

$$
\frac{\partial l}{\partial x}=\frac{K(l)}{l \times U(l)}
$$


where $K(l)$ and $U(l)$ are the turbulent diffusion coefficient and the wind speed at height $l$. Expressions for $K$ and $U$ are:

$$
\begin{aligned}
& K(l)=\frac{\varkappa l u_{*}}{\phi_{\mathrm{c}}(l / z)} \\
& U(l)=\frac{u_{*}}{\varkappa}\left\{\ln \left(l / z_{\mathrm{o}}\right)-\Psi_{\mathrm{m}}(l / L)\right\}
\end{aligned}
$$

The function $\phi_{c}$ is the dimensionless concentration gradient in the surface layer (equal to the function for potential temperature and specific humidity) and $\Psi_{m}$ is the stability correction function to the logarithmic wind profile. The Obukhov length $L\left(=-u_{*}{ }^{3} T_{Q_{\mathrm{a}}} C_{p} / x g H_{\mathrm{o}}\right)$, with $\varrho_{\mathrm{a}}$ for air density, $T$ for absolute temperature, $C_{p}$ for specific heat at constant pressure, $g$ for the gravitational acceleration, and $H_{\mathrm{o}}$ for the surface heat flux) is the characteristic length scale that determines the stability of the atmospheric surface layer. The symbols $u_{*}$ and $\varkappa$ represent the friction velocity and the von Karman constant $(=0.4)$, respectively. We adopt the following expressions for $\Psi_{\mathrm{m}}$ and $\phi_{c}$ and the stability correction function to the concentration profile, $\Psi_{c}$, as a function of $z / L$ (see Dyer, 1974; van Ulden \& Holtslag, 1985; Holtslag \& de Bruin, 1988):

for $L<0$ :

$$
\begin{aligned}
& \Psi_{\mathrm{m}}=2 \ln \left[\frac{1+p}{2}\right]+\ln \left[\frac{1+p^{2}}{2}\right]-\tan ^{-1}(p)+\frac{\pi}{2} \\
& \Psi_{c}=2 \ln \left[\frac{1+q}{2}\right]
\end{aligned}
$$

with $p=(1-16 z / L)^{1 / 4}$ and $q=(1-16 z / L)^{1 / 2}$

$$
\phi_{\mathrm{c}}=(1-16 z / L)^{-1 / 2}
$$

and for $L>0$ :

$$
\begin{aligned}
& \Psi_{\mathrm{m}}=\Psi_{c}=-0.7 \frac{z}{L}-\left(0.75 \frac{z}{L}-10.72\right) \exp \left(-0.35 \frac{z}{L}\right)-10.72 \\
& \phi_{c}=1+0.7 \frac{z}{L}+\frac{z}{L}\left(4.502-0.2625 \frac{z}{L}\right) \exp \left(-0.35 \frac{z}{L}\right)
\end{aligned}
$$

The solution of A.4 in the surface layer can be approximated by (van Wijk et al., 1989):

$$
l\left\{\ln \left(\frac{l}{z_{0}}\right)-\Psi_{\mathrm{m}}\left(\frac{l}{L}\right)-1\right\} \phi_{c}\left(\frac{l}{4 L}\right)=\varkappa^{2} x
$$


This implicit expression can be solved iteratively for specified values of $z_{0}, L$ and $x$. The functions $\Psi_{\mathrm{m}}$ and $\phi_{\mathrm{c}}$ are specified in Equations A.7, A.9, A.10 and A.11, where the functional dependence on $z / L$ has to be replaced by $l / L$ in $\Psi_{\mathrm{m}}$ and by $l /(4 L)$ in $\phi_{c}$. For $l / L=0$ this expression reduces to the neutral one used for small experimental fields with a very shallow internal boundary layer. The concentration profile in the internal boundary layer is assumed to be the equilibrium profile:

$$
\begin{aligned}
& C-C_{\mathrm{o}}=\frac{-R}{\mathcal{H} u_{*}}\left\{\ln \left(\frac{z}{z_{\mathrm{o}}}\right)-\Psi_{c}\left(\frac{z}{L}\right)\right\} \\
& \text { with } C_{\mathrm{o}}=C_{\mathrm{s}}-R\left(r_{\mathrm{s}}+r_{\mathrm{b}}\right)
\end{aligned}
$$

Since the concentration at $z=l$ has to match the background concentration $C_{\mathrm{a}}$, we can solve for $R$ and express the result in terms of an aerodynamic resistance:

$$
r_{\mathrm{a}}=\frac{1}{\varkappa u_{*}}\left\{\ln \left(\frac{l}{z_{\mathrm{o}}}\right)-\Psi_{c}\left(\frac{l}{L}\right)\right\}
$$

For the averaged volatilization over the entire field, we again suggest applying the result for the downstream end of the field because the surface flux varies only slightly with $x$.

In summary, the following calculation procedure can be adopted, assuming that $u_{*}, z_{0}, L$ and the length of the field $L_{x}$ are known. First calculate the internal boundary layer height $l$ from A.12 with $x=L_{x}$ in an iterative way. The functions $\Psi_{\mathrm{m}}$ and $\phi_{\mathrm{c}}$ are specified in A.7 and A.9. When $l$ is known, $r_{\mathrm{a}}$ follows directly from A.14 with $\Psi_{c}$ as specified in A.8.

In practical situations the Obukhov length $L$ and the friction velocity $u_{*}$ are often not known. When these parameters are not available from direct measurements, we recommend using the methods developed by Holtslag \& van Ulden (1983) and van Ulden \& Holtslag (1985). They provide schemes that enable the estimation of $u_{*}$ and $L$ on the basis of routine observations of wind speed and cloud cover. A software implementation is described by Beljaars et al. (1989) and Beljaars \& Holtslag (1989). The software package is freely available from the Royal Netherlands Meteorological Institute for research applications.

\section{References}

Beauchamp, E. G., G. E. Kidd \& G. W. Thurtell, 1982. Ammonia volatilization from liquid dairy cattle manure in the field. Canadian Journal of Soil Science 62: 11-19.

Beljaars, A. C. M. \& A. A. M. Holtslag, 1990. A software library for the calculation of surface fluxes over land and sea. Environmental Software 5 (in press).

Beljaars, A. C. M., A. A. M. Holtslag \& R. M. van Westrhenen, 1989. Description of a software library for the calculation of surface fluxes. KNMI Technical Reports, TR-89-01.

Blom, J. \& L. Wartena, 1969. The influence of changes in surface roughness on the development of turbulent boundary layer in the lower layers of the atmosphere. Journal of the Atmospheric Sciences 26: $255-265$. 
Bolt, G. H., 1976. Transport and accumulation of soluble soil components. In: G. H. Bolt \& M. G. M. Bruggenwert (Eds), Soil Chemistry, A. Basic Elements, p. 126-140. Elsevier Scientific Publishing Company, New York.

Bruckler, L., B. C. Ball \& P. Renault, 1989. Laboratory estimation of gas diffusion coefficient and effective porosity in soils. Journal of Soil Science 147: 1-10.

Brutsaert, W., 1982. Evaporation into the atmosphere. Reidel, Dordrecht, The Netherlands, 299 pp.

Dyer, A. J., 1974. A review of flux-profile relationships. Boundary-Layer Meteorology 7: 363-372.

Elliott, W. P., 1958. The growth of the atmospheric internal boundary layer. Transactions of the American Geophysical Union 39: 1-48.

Gordon, R. M., M. Y. Leclerc, P. Schuepp \& R. Brunke, 1988. Field estimates of ammonia volatilization from swine manure by a simple micrometeorological technique. Canadian Journal of Soil Science 68 : 369-380.

Hales, J. M. \& D. R. Drewes, 1979. Solubility of ammonia at low concentrations. Atmospheric Environment 13: 1133-1147.

Holtslag, A. A. M. \& H. A. R. de Bruin, 1988. Applied modeling of the nighttime surface energy balance over land. Journal of Applied Meteorology 27: 689-704.

Holtslag, A. A. M. \& A. P. van Ulden, 1983. A simple scheme for daytime estimates of the surface fluxes from routine weather data. Journal of Climatology and Applied Meteorology 22: 517-529.

Jensen, N. O., E. L. Petersen \& I. Troen, 1984. Extrapolation of mean wind statistics with special regard to wind energy applications. WCP, WMO/TD-15, Geneva, $85 \mathrm{pp}$.

Jury, W. A., W. F. Spencer \& W. J. Farmer, 1983. Behavior assessment model for trace organics in soil. I. Model description. Journal of Environmental Quality 12: 558-564.

Molen, J. van der, D. W. Bussink, N. Vertregt, H. G. van Faassen \& D. J. den Boer, 1989. Ammonia volatilization from arable and grassland soils. In: K. Henriksen (Ed.), Nitrogen in Organic Wastes Applied to Soils, p. 185-201. Academic Press, London.

Molen, J. van der, H. G. van Faassen, M. Y. Leclerc, R. Vriesema \& W. J. Chardon, 1990. Ammonia volatilization from arable land after application of cattle slurry. 1. Field estimates. Netherlands Journal of Agricultural Science 38: 145-158.

Pasquill, P., 1972. Some aspects of boundary layer description. Quarterly Journal of the Royal Meteorological Society 98: 468-494.

Stull, R. B., 1988. An introduction to boundary layer meteorology. Kluwer Academic Publishers, Dordrecht, $666 \mathrm{pp}$.

Taylor, P. A. \& R. J. Lee, 1984. Simple guidelines for estimating wind speed variations due to small scale topographic features. Climatological Bulletin (Canadian Meteorological Oceanographic Society) 18: 3-22.

Townsend, A. A., 1965. The response of a turbulent boundary layer to abrupt changes in surface conditions. Journal of Fluid Mechanics 22: 799-822.

Ulden, A. P. van, 1978. A simple estimate for vertical diffusion from sources near the ground. $A t$ mospheric Environment 12: 2125-2129.

Ulden, A. P. van, \& A. A. M. Holtslag, 1985. Estimation of atmospheric boundary layer parameters for diffusion applications. Journal of Climatology and Applied Meteorology 24: 1196-1207.

Wijk, A. J. M. van, A. C. M. Beljaars, A. A. M. Holtslag \& W. C. Turkenburg, 1990. Diabatic wind speed profiles in coastal regions: Comparison of an internal boundary layer model with observations. Boundary-Layer Meteorology (in press).

Wieringa, J., 1986. Roughness-dependent geographical interpolation of surface wind speed averages. Quarterly Journal of the Royal Meteorological Society 112: 867-889.

Wilson, J. D., G. W. Thurtell, G. E. Kidd \& E. G. Beauchamp, 1982. Estimation of the rate of gaseous mass transfer from a surface source plot to the atmosphere. Atmospheric Environment 16: 1861-1867.

Yuan-Hui, L. \& S. Gregory, 1974. Diffusion of ions in sea water and in deep-sea sediments. Geochimica et Cosmochimica Acta 38: 703-714. 